\title{
Autonomy, liberalism and advance care planning
}

\author{
Sharon Ikonomidis and Peter A Singer University of Toronto, Canada
}

\begin{abstract}
The justification for advance directives is grounded in the notion that they extend patient autonomy into future states of incompetency through patient participation in decision making about end-of-life care. Four objections challenge the necessity and sufficiency of individual autonomy, perceived to be a defining feature of liberal philosophical theory, as a basis of advance care planning. These objections are that the liberal concept of autonomy (i) implies a misconception of the individual self, (ii) entails the denial of values of social justice, (iii) does not account for justifiable acts of paternalism, and (iv) does not account for the importance of personal relationships in the advance care planning process. The last objection is especially pertinent in light of recent empirical research highlighting the importance of personal relationships in advance care planning.

This article examines these four objections to autonomy, and the liberal theoretical framework with which it is associated, in order to re-evaluate the philosophical basis of advance care planning. We argue that liberal autonomy (i) is not a misconceived concept as critics assume, (ii) does not entail the denial of values of social justice, (iii) can account for justifiable acts of paternalism, though it (iv) is not the best account of the value of personal relationships that arise in advance care planning. In conclusion, we suggest that liberalism is a necessary component of a theoretical framework for advance care planning but that it needs to be supplemented with theories that focus explicitly on the significance of personal relationships.
\end{abstract}

(Fournal of Medical Ethics 1999;25:522-527)

Keywords: Medical ethics; patient autonomy; liberalism; advance directives

A component of advance care planning, advance directives allow individuals to specify in advance the type of medical interventions they want, and do not want, to receive, and the person(s) they want to make decisions on their behalf, if or when they become incapable of making treatment decisions themselves. To date, it has been assumed that advance directives should be honoured since they respect, or at least aim to respect, the value of patient autonomy. ${ }^{1}$ Concern for autonomy stems from "people's interest in making significant decio sions about their lives for themselves and accors? ing to their own values or conception of a goo life". ${ }^{2}$ By enabling a competent person "extend" his or her autonomous decision-making capacity into a future state in which this capacif no longer exists, ${ }^{3}$ an advance directive presumabN gives a person some control over the end of his or her life. ${ }^{4}$

Although the liberal value of autonomy has this far been the philosophical basis of advance diree tives, its necessity and sufficiency have recent been challenged. Four objections suggest that autonomy, perceived to be a defining feature of liberal philosophical theory, is insufficient of $₫$ basis of advance care planning. These objectmigs are that the liberal concept of autongm (i) implies a misconception of the individual sef (ii) entails the denial of values of social justic\&, (iii) does not account for justifiable acts of pate nalism, and (iv) does not account for the importance of personal relationships in the process of advance care planning. The last objee tion is especially pertinent in light of recent empirical research highlighting the importance of personal relationships in advance care planning. This article examines these four objections autonomy, and the liberal theoretical framework with which it is associated, in order to re-evalua the philosophical basis of advance care planning.

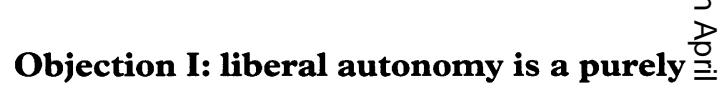
individualistic concept

The first major objection to liberal autonomy that it implies a misconception of the self as rational, independent agent who is ultimate $\theta$ "unencumbered" or "disengaged" from all social context and who is capable of making decisions ways that are essentially detached from othơ human beings. ${ }^{8}$ An ethic of individual autonom; critics claim, cannot serve as a basis for advan care planning unless those engaged in the planning process make treatment decisions in way that is removed from the interests of othereे 
But patients do not make treatment decisions strictly on a self-regarding basis and are, rather, essentially attached to the lives of others, particularly those close to them such as family members. ${ }^{9}$ The patient is too enmeshed in a network of relations to others to be properly singled out as a selfsufficient decision maker. ${ }^{10}$ Thus, autonomy cannot mean simply a person's right to choose for herself based on personal interests alone; others' interests are necessarily a factor in the process of decision making.

Similarly, communitarians have argued that a liberal conception of autonomy is deficient since it both wrongly portrays the individual as essentially disconnected from the rest of the community and since it demands the denial of the priority of communal values. The communitarian concept of the self is constituted by its ends-ends that are not chosen but rather are discovered by virtue of our being embedded in some shared social context. Individual identity, and hence individual capacity for choice, is not separate from but rather structured by these ends and the roles the individual assumes with respect to the community. ${ }^{11}$ The communitarian self is "narrative", ie, a self partly constituted by a life story with a certain end, or telos, ${ }^{12}$ which is "intersubjective". ${ }^{13}$

Accordingly, the moral agent is not properly viewed in an atomistic, dislocated way, as is associated with liberal theory, but rather is situated in a moral community from which moral identity, convictions, and judgments derive. ${ }^{14}$ The liberal autonomous self, perceived by communitarians as one able to stand apart from, question and revise its convictions of the good life, is mistakenly defined as prior to its ends and as having a virtually unlimited capacity for choice.

Contemporary liberalism, though, is not a purely individualistic ethic. Liberal conceptions of autonomy have always revealed an underlying general concept understood in terms of selfgovernment, self-determination, or a kind of selfownership of values, beliefs, desires, and choices - in other words in terms of a life that is not "other-governed". Yet, contemporary liberal interpretations of autonomy are expressed in terms of negative freedom, rank-ordered desires, personal identification, and, notably, historical formation $^{15}$ which highlights the broad social embeddedness of the individual.

This modern liberal concept of autonomy is an essentially historical notion in that the conditions that must be met in order for desires to be autonomous are properties of the formation of, and not mere identification with, those desires. ${ }^{16}$ What is crucial in the determination of whether a desire is autonomous is the manner in which the desire was formed, which may have little to do with how the agent evaluates the desire itself. ${ }^{17} \mathrm{~A}$ person is autonomous when he or she understands the development of and changes in his or her character. What modern liberalism thus strives to preserve and promote in terms of individuals' autonomy is their ability to reflect on the manner they develop as persons and on the social and cultural conditions that shape that development through history.

Though the liberal self has been described as "atomistic" and "independent" in that "the fulcrum of the determination of autonomy remains the point of view of the agent", ${ }^{18}$ this does not mean that individuals are able to dislocate themselves from their social and historical context. We are able to judge ourselves only in the light of our social and cultural histories and the manner in which they affect and shape our development as persons. Modern liberals recognise that it is impossible to think of ourselves except as part of ongoing communities, defined by reciprocal bonds of obligation, common traditions, and institutions. Liberal conceptions of autonomy therefore are not purely individualistic, as critics claim.

Liberals have always deplored the effects on individuals of social manipulation, the condition in which individuality is swallowed up by the collective mass. ${ }^{19}$ The liberal concept of autonomy portrays the individual as a separate being with a distinct personal point of view and an interest in being able to pursue securely his or her own conception of the good, but it does not presume that one is only accidentally and externally related to others. $^{20}$ Modern liberalism is not necessarily objectionably individualistic given that the liberal autonomous agent may be driven by choices whose origins are outside his or her control. Where such so called autonomous choices are expressed, the interests of the individual may be outweighed by the considerations of others, as discussed in the next section.

\section{Objection II: liberal autonomy entails the denial of social justice}

There exists a potential conflict between the principles of autonomy and justice where patients appear to have the right to claim whatever resources they want regardless of the impact of their decisions on the welfare of others. ${ }^{21}$ To critics who perceive liberal theory as a framework for the exaggerated promotion of individual autonomy, it may not be clear how liberalism can account for advance care planning when the 
interests of society outweigh those of the individual. Practically speaking, all requests cannot and should not be honoured simply because they represent the autonomous wishes of the individual.

Although advance directives have been used mainly to limit treatment, requests for treatment may cause conflicts between competent individuals' wishes and the health services that are available to them once they become incompetent. For example, advance directives asking for scarce treatments may be overridden when a "just level" of care is exceeded and others are being denied resources. ${ }^{22}$ Patient choice also may be limited when treatment is too costly, especially given that other health needs are not met. ${ }^{23}$

Accordingly, under a universal health care plan like that in Canada, the autonomy of patients who demand services that are not provided under the unified public plan might be restricted.$^{24}$ In other words, patients might not have a legitimate claim to treatment that is being withheld as part of a just rationing system..$^{25}$ Privileging the value of autonomy runs against a principled way of limiting the medical services that ought to be guaranteed to all individuals. ${ }^{26}$ Even in Canada where the emphasis on universal access to health care services is based on collectivist principles that call for social responsibility for the basic welfare of its members, ${ }^{27}$ a significant dilemma exists since the state both protects individual autonomy by providing for an individual's welfare and threatens it by making allocation dependent on the consent of the plurality. ${ }^{28}$

The promotion of autonomy in advance care planning must be understood not as a guarantee that the patient will get whatever he or she wants, but rather as "the responsible use of freedom" according to which the right course of action is not always one that promotes his or her own interests. This has been described as a "socially responsible" approach to advance directives according to which the patient is viewed as both citizen and consumer and patient selfdetermination is understood in the context of "informed consent" rather than in the context of "consumer sovereignty". ${ }^{25}$ A "citizen ethic" according to which the patient is viewed as a citizen with rights within the health care context along with duties to make judicious and proportionate choices also has been proposed. ${ }^{29}$

Though critics often assume that autonomy is the trump value within liberalism, leaving little or no room for an account of justice and equitable resource allocation, this is not a valid assumption. The contemporary liberal objective may be summarised as follows: if we are to treat people as equals, we must protect them in their possessio of certain rights and liberties. ${ }^{30}$ Much has beem written within liberalism on the question of which rights and liberties these are, but the mored demand of liberal equality is held prior to that the protection of our (individual) rights and freedoms.

Justice as fairness, understood in terms of equal share of social goods, namely, equal liberti and opportunities, is the very crux of moderco liberalism. ${ }^{31}$ Modern liberals reject the claim that liberalism is committed merely to econom $\overrightarrow{r e}$ growth; the government required to ensure this growth, and a conception of life in which growth pursued for its own sake in the form competition, individualism, and materi\$ pursuits. ${ }^{32}$ Liberty is an important value but whâ is valued fundamentally is equal liberty for all citis zens. Liberalism is a political theory based on egalitarian conception of justice. Liberal theory thus able to take into account the concerns for equitable resource allocation that may arise advance care planning.

Objection III: liberal autonomy does not $\vec{\oplus}$ account for justifiable acts of paternalisisne The third major objection to liberal autonon that it is very difficult, if at all possible, for line? als to justify paternalistic acts. This poses a prote lem in defining a liberal account of advance cane planning since substitute decision makers an sometimes justified in treating incompete patients paternalistically when to honot patient's wishes as expressed when competent would pose an unnecessary risk to the patien present welfare.

Liberals insist that in order to lead a good life "every competent adult be provided with a sphe of self-determination which must be respected by others" 33 and that "for those who pass the threo hold of age and mental competence, the right be self-determining in the major decisions in life inviolate". ${ }^{33}$ However, the modern liberal princs ple of autonomy must be qualified by a paternat istic principle of wellbeing. Paternalistic acts my be justified in our relationships with children, the demented, the otherwise temporarily incapacs tated, and even, under certain circumstances, ffil our relationships with competent adults who exhibit "weakness of will" in doing what is in the best interests. ${ }^{34}$

Liberals call attention to the distinction between "hard paternalism", which justifies the impositio of values and judgments on people "for their ow good", and "soft paternalism" which holds that the state has the right to prevent self-regarding harm: 
ful conduct when that conduct is non-voluntary (a "non-voluntary" act is one for which consent is "missing because the subject...is incapable of giving his voluntary consent"). ${ }^{35}$ Soft paternalism is a principle which suitably qualifies liberalism since it permits interference in the absence of voluntary consent. Soft paternalism defends those who are unable to give voluntary consent against threats to their autonomous self, which is quite another thing than throttling that autonomous self with external coercion. It may even defend those who are no longer "the same person" as the person who issued the advance directive. (This touches upon a further argument against advance directives - that they often apply to people who are different from those who executed them; a full consideration of this primarily metaphysical argument is beyond the scope of this article. ${ }^{36}{ }^{37}$ Interference on this ground is no more illiberal than interference to prevent one from harming an unwilling second party. ${ }^{38}$

Liberalism may thus be qualified by a principle of soft paternalism in the form of overriding the advance directives of patients who are now incapable of providing voluntary consent to available health care options. The choices expressed by patients while competent may not have been voluntarily made due to, for example, coercion and bias from health care professional(s) and/or family members. Paternalistic decision making may be acceptable under such circumstances to defend the patient against threats to his or her autonomous self.

The choices expressed by patients while competent may not have been adequately informed either-had they foreseen and understood the nature of their now present condition, such persons may have chosen otherwise. Paternalistic decision making may be acceptable under such circumstances in order to do what is in the patient's current best interests.

Soft paternalism is regarded as an "alternative, essentially liberal, rationale for most of what seems reasonable in paternalistic restrictions". ${ }^{39}$ Insofar as it is qualified by a principle of paternalism in defence of overriding patients' previously expressed choices, at least where those choices were not voluntary and/or informed and now threaten their wellbeing, contemporary liberalism is able to account for justifiable acts of paternalism within the process of advance care planning.

\section{Objection IV: liberal autonomy does not account for the importance of personal relationships}

This last objection is especially pertinent in light of recent empirical research highlighting the importance of personal relationships in advance care planning. In a qualitative study of 48 patients receiving haemodialysis, we showed that the traditional academic assumptions are not fully supported from the perspective of patients involved in advance care planning. The patients we interviewed stated that: 1) the purpose of advance care planning is not only preparing for incapacity but also preparing for death; 2) advance care planning is not based solely on autonomy and the exercise of control, but also on personal relationships and relieving burdens on others; 3 ) the focus of advance care planning is not only on completing written advance directive forms but also on the social process, and 4) advance care planning does not occur solely within the context of the physician/patient relationship but also within relationships with close loved ones. ${ }^{5}$ In a subsequent qualitative study of 140 people with Human Immunodeficiency Virus (HIV), we showed the primary goal of advance care planning was: preparing for death, which entailed facing death, achieving a sense of control, and strengthening relationships. ${ }^{6}$

It has been argued from within feminist theory that the overemphasised individualistic ethic which critics associate with liberalism, demands the denial of the value of personal relationships for autonomous choice. The (liberal) concept of autonomy, it is claimed, carries too many associations of isolation and independence in its portrayal of personhood to capture feminist conceptions of agency. ${ }^{40}$ As in the case of the first objection considered earlier, liberalism is charged with defining atomistic individuals as the basic units of political and legal theory. The further objection here, however, is that liberalism thus fails to recognise the inherently social nature of human beings and the "relatedness" that is a precondition of autonomy. ${ }^{+1}$

For example, relational theory, offered by "feminine theorists" from within feminist theory, ${ }^{42}$ argues that although appropriate to relationships between strangers and to purely professional relationships, emphasis on (liberal) autonomy is not appropriate to relationships based on "connectedness", or "caring". ${ }^{33}$ The concern for the value of personal relationships is captured in a morality of care that challenges justice-based theories of moral development and judgment $^{\text {t4 }}$ (ie, those associated with the liberal tradition). Such theories have been rejected as "masculine" approaches to moral decision making and ethical analysis having little, if any, concern for the interests of women. ${ }^{45}$ Moreover, they are often viewed as the presumption of Western (liberal) medical ethics which "often 
relies on ... the context of justification for ethical decision making rather than the context within which such decision making takes place...". ${ }^{46}$ Consequently, relational theorists have argued for the importance of context-based values such as that of personal relationships rather than abstract, universal principles. For example, it has been argued that an ethic of care is more appropriate as the foundation for theories of medical ethics than the liberal values of justice and autonomy in accounting for the significance of the value of personal relationships. ${ }^{46}$

It may be, however, that liberalism does not fail as a theoretical framework for the value of personal relationships for autonomy since it has never been its intention to serve in this role. Liberalism (with its ideal of state neutrality and "negative" conception of freedom) is best considered a political doctrine ${ }^{47}$ The liberal concern for political relationships reflects a deeper agenda to protect the private choices and affairs of individuals. Modern liberalism therefore may have relevance for a theoretical account of advance care planning, not in terms of the promotion of the value of personal relationships, but rather in terms of its preservation and protection. Liberal writers do not discuss the nature and value of personal relationships, as such, though they may seek to define a liberal account of the individual as situated or embedded in community and culture. This suggests that liberalism is not inconsistent with an account of the nature and value of personal relationships in advance care planning. It is not inconsistent with the concerns and goals people who engage in advance care planning have that relate to the impact of their decision making on others.

However, a relationship ethic serves specifically as an account of the importance of personal relationships in the process of advance care planning. After all, such an ethic has explanatory power insofar as it defines moral decision making, for instance regarding certain decisions about future care, as part of particular and concrete situations in which individuals are engaged in networks of relationships with others. Insofar as it lacks a relationship ethic of this kind, modern liberalism remains insufficient in accounting for the importance of personal relationships as a factor in advance care planning.

\section{Conclusion}

Four objections suggest that the liberal value of autonomy is inappropriate as a basis of advance care planning. These objections are that the liberal concept of autonomy (i) implies a misconception of the individual self, (ii) entails the denial of values of social justice, (iii) does not account for justifiable acts of paternalism, and (iv) does nut account for the importance of personal relatio ${ }^{-}$ ships in the process of advance care planning. We have examined these four objections to autonom $\vec{z}$, and the liberal theoretical framework with which is associated, in order to re-evaluate the phile sophical basis of advance care planning.

We have argued that (i) liberal autonomy is nब a misconceived concept as critics assume. Though a necessary component of a theoretical account $\underline{\mathrm{o} f}$ the concern for personal control that persoffs engaged in advance care planning may have, liberal autonomy entails recognition of the sociel aspects of personhood and thus the social comp $\overline{\bar{\phi}}-$ nents of advance care planning. We have al\$ argued that liberal autonomy (ii) does not ent the denial of values of social justice and that it (ivit) can account for justifiable acts of paternalism consideration of a patient's advance directiv. With respect to the objection that liberalism (iv) does not account for the importance of persong 1 relationships in the process of advance care pla ning, we acknowledge that liberalism remains insufficient framework in terms of its lack of direet focus on the value of personal relationships thit are a factor in the process. In closing, we sugge that contemporary liberalism needs to be sup le mented with theoretical accounts-such as shat offered by relational theory-that pay specitec attention to the value of personal relationships towards the development of a full theoretical framework for advance care planning.

\section{Acknowledgements}

The authors are grateful to James Lavery, Douglias Martin and Barbara Secker for their commen and suggestions and to Professor Wayne Sumnor for supervising Sharon Ikonomidis's doctorăl thesis. This research was supported by the Physicians' Services Incorporated Foundation of O tario. Dr Singer was supported by a Nationgl Health Research and Development Program Scholar award and is now supported by a Medici Research Council of Canada Scientist award.

Sharon Ikonomidis, PhD, is a Doctoral Resear Graduate of the University of Toronto foint Centre fogr Bioethics. Peter A Singer, MD, MPH, FRCPC, is Sitn Life Chair in Bioethics at the University of Toronto, Director of the University of Toronto foint Centre for Bioethics, Professor of Medicine, University of Torontte and a Staff Physician at The Toronto Hospital. Please address all correspondence to: $\operatorname{Dr}$ Peter A Singer, ST Life Chair in Bioethics and Director, University $\$ f f$ Toronto foint Centre for Bioethics, 88 College Streę, 
Toronto, Ontario, M5G 1L4, CANADA, tel: 416978-4756, fax: 416-978-1911, e-mail: peter.singer@ utoronto.ca

\section{References and notes}

1 Emanuel LL, Barry MJ, Stoeckle JD, Ettelson LM, Emanuel EJ. Advance directives for medical care - a case for greater use. The New England fournal of Medicine 1991;324:889-95.

2 Brock DW. Good decisionmaking for incompetent patients. Hastings Center Report 1994; 24:s8-s11.

3 Hackler C, Moseley R, Vawter DE, eds. Advance directives in medicine: studies in health and human values. New York: Praeger, 1989.

4 Eisendrath SJ, Jonsen AR. The living will: help or hindrance? fournal of the American Medical Association 1983;15:2054-8.

5 Singer PA, Martin DK, Lavery JV, Thiel EC, Kelner M, Mendelssohn DC. Reconceptualizing advance care planning from the patient's perspective. Archives of Internal Medicine 1998; 158: $879-84$.

6 Martin DK, Thiel EC, Singer PA. A new model of advance care planning: observations from people with HIV. Archives of Internal Medicine, 1999;159:86-92.

7 Nelson HL, Nelson JL. Preferences and other moral sources. Hastings Center Report 1994; 24:s19-s21.

8 Teno JM, Hill TP, O'Connor MA. Advance care planning: priorities for ethical and empirical research. Hastings Center Report 1994;24:s1.

9 Hardwig J. What about the family? Hastings Center Report 1990; 20:5-10.

10 Blustein J. The family in medical decisionmaking. Hastings Center Report 1993; 23:6-13.

11 Sandel M, ed. Liberalism and its critics. New York: New York University Press, 1984:5-6.

12 MacIntyre A. After virtue: a study in moral theory. Notre Dame, Indiana: University of Notre Dame Press, 1984.

13 Sandel MJ. Liberalism and the limits of justice. New York: Cambridge University Press, 1982:ch 1.

14 Zwart H. Rationing in the Netherlands: the liberal and the communitarian perspective. Health Care Analysis 1993;1:53-6.

15 Christman J, ed. The inner citadel: essays on individual autonomy. Oxford: Oxford University Press, 1989

16 See reference 15:9.

17 Christman J. Autonomy and personal history. Canadian fournal of Philosophy 1991;21:1-24.

18 See reference 17:24.

19 Feinberg J. Autonomy. See reference 15:27-53.

20 See reference 10:10-11

21 Childress JF, Fletcher JC. Respect for autonomy. Hastings Center Report 1994;24:34-5.
22 Brock DW. Trumping advance directives. Hastings Center Report 1991;21:s5-s6.

23 Danis M. Following advance directives. Hastings Center Report 1994; 21:s21-s23.

24 Powers M. Efficiency, autonomy, and communal values in health care. Yale Law and Policy Review 1992;10:316-61.

25 Weber LJ. The patient as citizen and consumer: socially responsible education about advance directives. Professional Ethics 1993;2:113-27.

26 Emanuel EJ. A communitarian health-care package. The Responsive Community 1993;3:49-56.

27 Clark PG. Ethical dimensions of quality of life in aging: autonomy vs collectivism in the United States and Canada. The Gerontologist 1991;31:631-9.

28 Weinberg JK. Whose right is it anyway? Individualism, community, and the right to die: a commentary on the New Jersey experience. Hastings Law fournal 1988;40:119-67.

29 Danis M, Churchill LR. Autonomy and the common weal. Hastings Center Report 1991;21:25-31.

30 Kymlicka W. Contemporary political philosophy: an introduction. Oxford: Clarendon Press, 1990:50

31 Rawls J. Political liberalism. New York: Columbia University Press, 1993.

32 Dworkin R. A matter of principle. Massachusetts: Harvard University Press, 1985.

33 See reference 30:100.

34 See reference 30:232.

35 Feinberg J. Harm to self: the moral limits of the criminal law [vol 3]. Oxford:Oxford University Press, 1986:12, 345.

36 Dworkin RM. Life's dominion: an argument about abortion, euthanasia, and individual freedom. New York: Knopf, 1993.

37 Dresser R. Dworkin on dementia: eloquent theory, questionable policy. Hastings Center Report 1995;15,6:32-8.

38 See reference 35:14

39 See reference 35:26.

40 Sherwin S. No longer patient: feminist ethics and health care. Philadelphia: Temple University Press, 1992:156.

41 Nedelsky J. Reconceiving autonomy: sources, thoughts and possibilites. Yale fournal of Law and Feminism 1989;1:7-36.

42 See reference 40:49.

43 See reference 41 . Nedelsky, along with other relational theorists who reconceive autonomy in terms of relationships, is an exception to this pool of theorists.

44 Gilligan C. In a different voice: psychological theory and women's development. Cambridge: Harvard University Press, 1982.

45 Fry ST. The role of caring in a theory of nursing ethics. Holmes EB, Purdy LM, eds. Feminist perspectives in medical ethics. Bloomington: Indiana University Press, 1992:93-106.

46 See reference 45:94.

47 Larmore CE. Patterns of moral complexity. Cambridge: Cambridge University Press, 1987. 